\title{
SIMBOLOGIA DOS SONHOS E CULTURALIDADE
}

\section{Ivan dos Santos Messias}

\begin{abstract}
Autor correspondente: Ivan dos Santos Messias - imessias@yahoo.com.br
*Professor na Pós-Graduação do Centro de Estudos Pesquisa, Extensão e Desenvolvimento Humano.

Mestre em Cultura e Sociedade pela Universidade Federal da Bahia. Graduação em Letras Vernáculas com Língua Inglesa pela Universidade Católica do Salvador.
\end{abstract}

\begin{abstract}
Resumo
Este artigo objetiva analisar os símbolos das manifestações oníricas destacando seu caráter terapêutico e culturalista, pois cada comunidade tem chave própria para interpretar os sonhos, a partir dos códigos de sua herança cultural. Os sonhos fornecem suportes significativos para o equilíbrio e administração da vida. Para sustentar os argumentos sobre estados oníricos, são analisados conceitos relacionados à Multiculturalidade, e alguns conceitos como arquétipo e Inconsciente Coletivo da teoria de C. Jung - indicativos de que, embora os sonhos possuam aspectos universais, temas comuns a todas as culturas - são interpretados pelas particularidades do cotidiano do sonhador e da comunidade na qual está inserido. O presente artigo acrescenta aos estudos em Psicologia que as expressões oníricas nem sempre atuam conforme as disposições internas do corpo, nem conforme os arquétipos e símbolos, haja vista que são episódios ou instantes em movimento, com muitas possiblidades criativas. Tal perspectiva solicita novas metodologias terapêuticas e interpretativas, solicita uma abordagem mais culturalista na investigação sobre os exercícios oníricos. Para a realização deste estudo, foram investigados relatos, vídeos, enunciados de pessoas participantes da cultura religiosa católico-afro-indígena no Brasil. A partir de relatos e códigos da cultura religiosa brasileira, são analisados costumes específicos e práticas simbólicas da cultura brasileira no século XXI. A relação sexual, a alimentação e a conduta cotidiana, por exemplo, são elementos culturais ligados aos estados oníricos e são analisados a partir da teologia simbólica da cultura brasileira. O estudo conclui que as imagens ancestrais e inconscientes fornecem ao organismo humano respostas para conflitos e empecilhos na trajetória de vida. Daí há necessidade de gerar novas pesquisas, a fim de conhecer mais rigorosamente os estados oníricos.
\end{abstract}

Palavras-chave: Arquétipo; Inconsciente coletivo; Culturalidade; Sonho. 


\title{
SIMBOLOGY OF DREAMS AND CULTURALITY
}

\begin{abstract}
This paper aims to analyze the symbols of the dream expressions, highlighting their therapeutic and cultural aspects, because every community has its own key for interpreting dreams, from the codes of their cultural heritage. Dreams provide important supports for balance and administration of life. To sustain the arguments about dream states, concepts related to Multiculturalism and some Jung's concepts like Archetype and Collective Unconscious are analyzed. It indicates that although dreams have universal aspects - themes common to all cultures - they are interpreted by the dreamer's daily specificities and the community in which they live. This article adds to the studies in psychology that dream expressions do not always act in accordance with the internal rules of the body, not as archetypes and symbols. They are episodes or moments in motion with many creative possibilities. This perspective calls for new therapies and interpretative methodologies; it requests more cultural approaches to research onto the dream activities. For this study, reports were investigated, videos, statements of people participating in the catholic-african-indigenous religious culture in Brazil. From reports and codes of Brazilian religious culture are analyzed specific customs and symbolic practices of Brazilian culture in the twenty-first century. Sexual relations, food and everyday behavior, for example, are cultural elements linked to the dream states and are analyzed from the symbolic theology of Brazilian culture. The study concludes that the ancestors and unconscious images provide the human organism responses to troubles. So that it is necessary to develop new researches to know better the dreamstates.
\end{abstract}

Keywords: Archetypes; Collective Unconscious; Culturality; Dream.

\section{INTRODUÇÃO}

O objetivo deste artigo é analisar os desdobramentos dos sonhos, cujas funções incidem na conservação e manutenção do corpo humano. Este texto não se interessa pela origem ou causa das manifestações oníricas, nem pelos estímulos externos e internos, tão pouco se eles têm causa divina e espiritual. Importa destacar o quanto os sonhos são relevantes no processo terapêutico, como força psicológica, nos processos de equilíbrio e cura. Portanto, as manifestações e vantagens dos estados oníricos terão atenção especial. Consequentemente, será enfatizada a função terapêutica, o sentido, o sonho como imagem e metáfora, que qualificam as relações subjetivas e interpessoais.
Em suas pesquisas, o psicoterapeuta suíço, Carl Gustav Jung apresenta as manifestações oníricas como fonte de inspiração, anunciadores de novas perspectivas; elemento divinatório, natural, absorvente do passado, presente e futuro, restaurador da saúde. (1) As manifestações oníricas nos ligam a todas as épocas de onde pertencemos sem barreiras temporais. Pelos sonhos viajamos, encontramos respostas para frustrações, doenças, investimentos. Sem dúvida, os estados oníricos direcionam ações, estruturam e estabilizam a psique humana, anunciam realidades emancipatórias. Nesse sentido, o artigo de Kelly Bulkeley trata dos sonhos como fatores religiosos, ou seja, as pes- 
soas atribuem suas expressões oníricas à presença de espíritos comunicadores. A autora empreende uma fenomenologia dos sonhos baseada na culturalidade, na interpretação dada pelas pessoas pesquisadas.

Este artigo, portanto, interpreta os sonhos segundo uma padronagem identitário-religiosa (culturalidade) diferente da tradição freudiana (positivo-estrutural-antropocêntrica). Neste estudo, a culturalidade significa um pensar com matizes específicos, interpretação própria do mundo, dos fenômenos conforme os símbolos disponíveis, compartilhados em um espaço seja religioso, afetivo ou econômico.

A história dos sonhos esteve, por séculos, ligada à revelação dos interesses divinos. As narrativas do povo hebreu, por exemplo, tratam da importância social dos intérpretes de sonhos, bruxos e profetas, ávidos para galgar poder político e emancipação; hajam vista as histórias de José que se tornou governador egípcio por inclusive interpretar sonhos do faraó. O caso emblemático na literatura mundial é do anjo Gabriel que anunciou, numa visão, a vinda do Messias. Mas o glamour divino acabou em certos espaços pelo menos. No século XVI, introdução à Era Moderna, o Novum Organum, do filósofo Francis Bacon tentava aniquilar as metafísicas. "O intelecto humano é semelhante a um espelho que reflete desigualmente os raios das coisas e, dessa forma, as distorce e corrompe".(2) A partir desse período, tudo que estivesse ligado à religiosidade, à superstição, ao intelecto corrompido pelos "ídolos" e "escoras do intelecto" era alvo de desdém e descrédito, era desonesto epistemologicamente. Desde então, os fatos têm por natureza uma verdade chamada científica.

Para interpretar os sonhos, o século XIX consolidou concepções mais psicológico-antropocêntricas com análise da estrutura do objeto, sem transcendê-lo conforme esboçaram metodologicamente Aristóteles e Bacon antes do referido século. Sigmund Freud seguiu posteriormente tais ensinamentos criando técnicas e análise das neuroses, dos inconscientes e das manifestações oníricas.
"Deus morreu" - anunciava o filósofo alemão F. Nietzsche para caracterizar sentimentos, ceticismos, niilismos e práticas filosóficas do período dezenoventista. Esta frase nietzschiana é sequer antropocêntrica, ao contrário, há desdém à racionalidade iluminada; detecta uma Vontade, uma in consciência instintivo-milenar e caótica que se assemelha aos desvarios das manifestações oníricas.

Na metade do século $X X$, porém, Jung não só expande as interpretações de Schopenhauer, Nietzsche e Freud como também atribui um caráter simbólico, terapêutico aos estados mentais. "Qualquer psicólogo que tenha ouvido várias descrições de sonhos sabe que seus símbolos existem numa variedade muito maior que os símbolos físicos da neurose". (1:27) Sem dúvida, as explicações freudianas e da literatura que o revisa dão respostas e soluções para diversos problemas inscritos nas sociedades modernas, repressivas, maquinais dos séculos XIX e XX. Tratam de desejos e recalques, a partir de experiências do pacientes e "consulentes". Sem dúvida são resultados a partir do empírico, mas subjetivamente interpretado. Entretanto, o sonho não é um fenômeno que resulta dos estados emocionais e orgânicos apenas. Os sonhos possuem códigos silenciosos, secretos, são metáforas e metonímias apresentadas com inversões narrativas; produzem cultura religiosa, modos de vida, éticas, moralidades e reinvenção do cotidiano.

\footnotetext{
Os psicólogos evolucionistas têm usado novidades em genética anatomia comparativa e psicologia experimental para argumentar que a religião é formatada por predisposições mentais que são programadas dentro do cérebro humano por pressões seletivas da evolução ( p. 73).
}

Esse argumento de Bulkeley(3) é pertinente considerando o fato de que não há religião fora da mente humana. Mas o objetivo deste artigo não é confrontar argumentos científicos e religiosos. Aqui, interessa fundar-se no fato de que os sonhos são manifestações universais, existentes. Todos sonham, portanto, há um universalismo biológico, mas também metafísico, gerado inclusive pelos tipos de interpretação. A partir disso, é necessário 
constatar os benefícios das manifestações oníricas e realizar uma fenomenologia da produção sonífera. Os sonhos são um objeto científico porque existem; são um fato mental como a linguagem, o desejo, a frustração, o amor, a dor, o desajuste psíquico, a alegria.

\section{CONCEITUAÇÃO E PERIPÉCIAS DOS PROCESSOS MENTAIS}

Os filósofos alemães Schopenhauer e Nietzsche diziam que maior parte de nossas ações são inconscientes. As comprovações vieram depois com Freud e Jung, mediante pesquisas e práticas psicanalíticas através da hipnose, observação das complexidades esquizofrênicas, interpretação e análise dos sonhos mesmo com certos resultados especulativos. Posteriormente, Carl Jung ${ }^{(4: 53)}$ estende o conceito de inconsciente:

\footnotetext{
O inconsciente coletivo é uma parte da psique que pode distinguir-se de um inconsciente pessoal pelo fato de que não deve sua existência à experiência pessoal, não sendo portanto uma aquisição pes soal. Enquanto o inconsciente pessoal é constituído essencialmente de conteúdos que já foram conscientes e, no entanto, desapareceram da consciência por terem sido esquecidos ou reprimidos, os conteúdos do inconsciente coletivo nunca estiveram na consciência e portanto não foram adquiridos individualmente, mas devem sua existência apenas à hereditariedade. Enquanto o inconsciente pessoal consiste em sua maior parte de complexos, o conteúdo do inconsciente coletivo é constituído essencialmente de arquétipos.
}

As imagens oníricas e arquétipos constituem o inconsciente coletivo, que é herdado e comum a toda humanidade - um material inato e universal. O inconsciente coletivo se configura por conteúdos que se diferem dos traumas, das ideologias e complexos do inconsciente pessoal adquiridos na vida social e nos conflitos das relações humanas.

O inconsciente coletivo é constituído por arquétipos. Entretanto, é preciso salientar que nem toda imagem onírica é um arquétipo. As narrati- vas soníferas são infinitas, diversificadas e englobam capítulos, complementos e repetições por vezes do cotidiano, do passado, do futuro sem necessariamente recorrer a símbolos universais. Logo a simbologia e a conotação são momentos, são episódios seletivos dos estados oníricos. Tudo está numa dimensão extra-pessoal, constituindo uma dimensão dupla, de paridades mentais, numa complementariedade entre o pessoal histórico e a inconsciência herdada milenarmente.

"Os arquétipos são imagens inconscientes dos instintos". (4:54) Ademais, os arquétipos não possuem apenas uma imagem personificada como equivocadamente pensamos. Enganamo-nos ao pensar que um arquétipo aparece apenas em forma de monstros, batalhas, unicórnios, foices, caveiras, mulheres misteriosas. Jung(4:47) especifica os tipos de arquétipo

\footnotetext{
arquétipos de transformação. Estes não são personalidades, mas sim situações típicas, lugares, meios, caminhos, etc, simbolizando cada qual um tipo de transformação. Tal como as personalidades, estes arquétipos também são símbolos verdadeiros e genuínos que não podemos interpretar exausti-

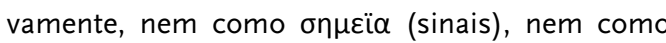
alegorias. São símbolos genuínos na medida em que eles são ambíguos, cheios de pressentimentos e, em última análise, inesgotáveis.
}

O caráter ambíguo e complexo dos símbolos os torna inesgotáveis, difíceis de serem apreendidos em sua totalidade. "O diagnóstico do inconsciente coletivo nem sempre é tarefa fácil". (4:55) ○ próprio Jung admite que "os conceitos de arquétipo e inconsciente tem dimensão ainda imprecisa, plástica, artificial embora tenha sido comprovado pela experiência". Tem razão. Embora seja difícil de captar conceitualmente, já não pode ser rebaixado à condição de material metafísico e abstrato, pois comprovadamente todos sonham. Pensando nisso, como definir e classificar os sinais, as metáforas e metonímias na expressão dos bêbados, esquizofrênicos, crianças os quais são exímios proprietários da linguagem com silenciamentos e imagens mesmo em estado de vigília? Isso pode ser 
chamado de extensão da manifestação onírica, inconsciente coletivo ou em qual classificação esse fenômeno se acomodaria?

É necessário acrescentar às reflexões de Freud e Jung que os componentes oníricos não se limitam aos arquétipos nem à variedade de simbologias. Tais recursos são alguns dos patrimônios dos sonhos cuja extensão extrapola as definições dadas por Freud e depois por Jung. Os arquétipos maternos e paternos, por exemplo, nem sempre se apresentam nos sonhos, pois os conteúdos oníricos se expandem além das narrativas clássicas, míticas, arquetípicas. Um sonho pode sequer apresentar símbolos ou metáforas e se referir apenas ao cotidiano imediato do sonhador. Existe infinitude do objeto, inexiste limite criativo. Logo, é arbitrário serem os sonhos classificados apenas pela existência dos arquétipos, das metáforas, dos símbolos, já que tais elementos nem sempre se apresentam nas manifestações oníricas.

"Durante toda a vida ao lado do pensamento recém-adquirido, dirigido e adaptado possuímos um pensamento-fantasia que corresponde a estado de espíritos ancestrais". ${ }^{(549)}$ Após termos compreendido os conceitos Junguianos, percebemos que os símbolos são de fato inesgotáveis devido à vastidão de possibilidades criativas, sobretudo curativas em suas orientações, sinais e advertências. Mas sua abertura e liberdade internas requerem métodos de apreensão alternativos, em vez de desdém acadêmico quanto à suposta incapacidade de ser objetificado.

Para realizar ciência é preciso delimitar, conceituar o objeto, mas como conhecer princípios de causalidade-efeito, dimensão e tempo se um objeto como o inconsciente, por exemplo, tem movimento incomum, impalpável, embora o sintamos, percebamos sua presença? Creio que haja mais um problema de definição que de materialidade - fácil observar, difícil descrever e mensurar. Caso raro: o significado antecede o significante. O próprio Jung( ${ }^{(4: 70)}$ assume sua indefinição conceitual acerca dos materiais imprecisos como arquétipo, inconsciente e anima. "A única coisa que pode ser esta- belecida com certeza no estado presente do nosso saber é nossa ignorância acerca da natureza do fato. Ou seja, como conhecer o inconsciente anímico". Ignorar nesse caso não significa desconhecer manifestações, causas, efeitos, composição, tempo - todos princípios fundamentais da ciência. Isso não significa que tal abordagem seja imaginaria e fictícia. O problema epistemológico se agrava quando Jung (4:108-109) afirma: "saber se a estrutura anímica e seus elementos isto é, os arquétipos tiveram origem de algum modo, é uma questão metafísica e não comporta por isso uma resposta". Parece ser contraditório, certo é que qualquer objeto tem como princípio a liberdade interna; tem a peripécia de escapar dos limites, determinações e nomenclaturas aplicados mesmo pelos mais eficientes e rigorosos métodos. Isso explica a revisão e a atualização constantes dos conceitos em todas as áreas do conhecimento. Pouco a pouco vamos percebendo a importância imediata de desvendar tamanho problema. Termos mudam, sentidos são ampliados e revisados.

\section{INTERPRETAÇÃO DOS SONHOS SOB ENFOQUE DA DIVERSIDADE CULTURAL}

Ter uma relação sexual maravilhosa nos sonhos normalmente não tem relação alguma com sexo. Os símbolos são imagens que substituem outro objeto, outro acontecimento. Os sonhos guardam linguagem simbólica. Consequentemente, as condições orgânicas e psicológicas como mal estar alimentar, frustração, recalque, neuroses são insuficientes para justificar a natureza dos sonhos. $\mathrm{Ou}$ seja, uma noite em que alguém está alegre pode produzir um sonho de tristeza, pessimismo e desastres. Uma alimentação inconveniente e estimulante pode gerar sonhos leves, otimistas, bem sucedidos. Visualizar facas, cães raivosos, assassinos tem significado positivo ou negativo depende do contexto e dos códigos linguísticos de cada povo, de cada pessoa. Portanto, o hipérbato das imagens ou inversão espaço-circunstancial é outra caracte- 
rística da linguagem onírica, que precisa ser meIhor analisada, agora mais sob o olhar culturalista e menos universalizante.

$\mathrm{Na}$ pesquisa sobre significados dos sonhos sagrados, Bulkeley(3) anotou os sonhos de 42 mulheres na graduação na Universidade Pública da $\mathrm{Ca}$ lifórnia, nos Estados Unidos. Foram 316 sonhos sobre tristeza, felicidade poderes místicos, culpa, inspiração, experiências artísticas. Maior parte associaram as mensagens como positivas, vozes de espíritos protetores, anjos. Esses depoimentos e relatos não são considerados puramente psicológicos, resultantes de repressão, idealização, projeção, recalque e outros. A análise do conteúdo dos sonhos místicos conclui que são extremamente positivos, com abundância de interações sociais amigáveis, emoções felizes, e boas perspectivas.

Depois de ter sonhos de simbologia promissora uma participante concede dinheiro a moradores de rua em gratidão ao sonho que fortaleceu sua fé em Deus intensamente. Da mesma forma procedem, no Brasil, os participantes de religiões índio-afro-europeu; dão pequenas quantias em dinheiro aos que vivem nas ruas e praças em agradecimento aos bons anúncios dos sonhos; vestem-se de branco, tocam o sino convocando bons tempos, dão flores, frutas e alimentos aos mares, aos rios, à terra, como no Japão, Índia, EUA, Inglaterra dos druidas místicos. Eternamente, o sonho preconiza a tradição, os rituais. A rainha Elizabeth da Inglaterra em 4 de junho de 2012, comemorou seu Jubileu de Diamante, ${ }^{(6)}$ passeou de barco no rio Thames, vestida de branco; soltaram foguetes, soaram o sininho como se faz em celebrações de umbanda brasileira - sinal de que estamos mais ligados do que imaginamos em matéria de rituais traçados pelos sonhos. As culturas parecem antagônicas, mas na verdade tem fundamentalmente práticas semelhantes, antigas, mundialmente.

Sonhar que está sendo arrastado pela turbulência das ondas marítimas, não tem nexo apenas com uma situação de caos e dificuldade na vida em vigília como afirma Hartmann, (7) seguindo a maneira Freud de interpretar os sonhos. Esta é uma interpretação possível, dentro de uma cultura específica. Cada interpretação atende a seu círculo social, gregário, identitário. As tradições epistemológicas psicanalíticas, por exemplo, explicam os sonhos ao seu modo: traumático, neurótico, arquétipos, processos inconscientes. Entretanto, o fato de estarmos dentro de uma tradição científica, argumentativa e racional não significa que possamos interpretar absolutamente a natureza dos sonhos, com metodologia ou direção única, universal.

As narrativas oníricas, suas mensagens em códigos produzem músicas, inventos, decisões, orientações em geral para beneficiar pessoas. Einstein afirmava que o conhecimento decisivo vinha da inspiração, do silêncio, da imaginação e não do conhecimento. O silêncio criativo é grande patrimônio da linguagem onírica. Pensar, pesquisar, falar, escrever, definir, categorizar produzem conhecimento. Esvaziar-se ou silenciar produzem soluções criativas e fórmulas de que o conhecimento limitado precisa para estabelecer-se com autoridade imponente. Enquanto os sonhos falam, os lábios permanecem fechados. $O$ intelecto consciente, antropocêntrico é um grão do Intelecto oculto, dentro do organismo humano. Desde os primórdios egípcio-hebraico advertia-se para o refrear da língua, o escutar dos sinais no corpo, no mundo, na natureza.

O pênis mergulha na vagina, nos lábios e ânus; a língua enrosca-se em outra língua, são imagens, metáfora, metonímias do silencioso para expressar que existe uma necessidade de ligação, de cópula com hábitos de vida mais sadios. Na perspectiva religiosa afro-brasileira, pênis simboliza o deus Exu, o qual vive na terra e no universo para introduzir o sêmen da informação e copular com a terra infernal dos humanos. Sexo simboliza ligação com o divino. Sonhos com relação sexual, casa, criança, assassinato, sangue, sequestro e nudez, por exemplo, indicam necessidade de reequilibrar-se, encontrar hábitos de vida harmônicos sadios, "divinos". Isso se realiza a partir de tratamentos com remédios, folhas, terapias diversas, festas, ofertas e rituais de encontro mais íntimo com os segredos e mistérios ocultos da natureza. As narrativas 
oníricas, portanto, produzem a etnicidade: a cultura, a culinária, as roupas, o jejum alimentar e sexual. Pessoas se vestem de branco como a rainha da Inglaterra, evitam lugares inóspitos, cumprem silêncio filosófico-comportamental na condição de membros das religiões índio-afro-católico brasileiras. A palavra oculto significa o que está por ser descoberto pela ciência. Assim avançam as descobertas e pesquisas laboratoriais na ansiedade de descobrir o oculto, que existe na natureza e no plano da ignorância humana.

"A Jurema quando nasce, a ciência ela já traz". Essa frase da música cantada no culto sagrado de Mestra Jurema Ritinha, ${ }^{(8)}$ no Recife, revela que o conhecimento praticado pelos cultos com saberes milenares, intuitivos, hiper-racionais são enunciados do transe, da mente em sono profundo; são templos de cura das doenças; lugares de conseIhos e orientações - casas de religiosos de Catimbó, Umbanda, Candomblé, Jurema, Nkisses, Exus, Orixás, Caboclos, todos brasileiros, mas em todo o planeta é assim. Não importa o nome das práticas. A denominação varia conforme a região, a língua, porém todos têm a mesma função: a de resguardar a dignidade, a saúde, a compreensão, a conduta ética, o equilíbrio das pessoas. Evidente que existem falhas humanas, abusos, subjetividades interseccionando os processos de real equilíbrio. Cada um desses espaços religiosos brasileiros guardam semelhanças e diferenças de procedimentos entre si. Esses cultos são ciência do presente, passado e futuro, nos quais as sacerdotisas e sacerdotes operam com os estados mentais do sono, do transe e da vigília. Assim, nascem comunidades religiosas, aparentemente heterogêneas, mas baseadas na ancestralidade universal.

Atualmente, quando alguém sonha com corda transformando-se em cobra, repete uma narrativa mítica, bíblica, quando Moisés e Aarão, buscando liberdade diante do rei, lançam ao chão uma vara que se transforma em cobra. ${ }^{(9)}$ Uma narrativa universal que transpõe o tempo. Entretanto, a cobra se vermelha e preta tem um significado, se azul e dourada tem outro, de acordo com os códigos orais reli- giosos umbandista-candomblecista no Brasil. Pode indicar traição, saúde, êxito, mudança, de acordo com o contexto do sonhador. Aqui, o arquétipo (ou imagem arcaica) foi utilizado para ampliar significados de novas necessidades pessoais. $O$ vermelho e preto da cobra se referem a fogo, mas também à terra. Tal simbologia se dirige à necessidade votiva de proteção pelos elementos físico-químicos fogo-terra do deus Exu enviado por Omolu, deus da cura de doenças ósseas, sanguíneas e de pele. Este conhecimento não é patrimônio de africanos, brasileiros, pretos, brancos exclusivamente; é uma energia telúrica da humanidade, adquirido através de exercícios, disciplina, renúncias, perseverança, silêncio mental, sono, transe e sinais. Heráclito dizia que a vida fala por sinais. Então cada sinal onírico solicita um tipo de ritual, seja uma oferta para a terra, ar, fogo, água, florestas. As ofertas podem ser flores, frutas, verduras, alimentos em geral. Cada imagem simbólica do inconsciente é interpretada como uma mensagem do elemento ar (Lemba), fogo (Zazi), Água (Logunedé), terra (Omolu).

E o ciclo se repete. Após tais imagens mentais com Omolu e outros arquétipos, são realizadas terapias através de banhos, jejum sexual e alimentar. São práticas filosóficas milenares, herança oculta, eterna. As energias calor, eletricidade, água, ar compõem o organismo de todos os seres vivos produzindo comunicação sobre profilaxias e interação com o meio ambiente. Segundo a referida tradição religiosa, os deuses são forças da natureza chamados Orixás estão em todos os seres humanos: travestis, mendigos, ricos, gente de toda cor, europeus, japoneses, norte-americanos, brasileiros. "O self possui uma religiosidade natural". (10:14) Nos escritos Junguianos, a religião é a meta, o ideal humano, a fusão entre ego e self, entre consciente e inconsciente com seus símbolos arquétipos e mitos constituindo a individuação, o ser integral. Quem sabe seja uma idealização, porém em algum lugar e momento um ser integral deve se desenhar.

Nossa psique faz parte da natureza e o seu enigma é igualmente sem limites. Assim "não pode- 
mos definir nem a psique nem a natureza - afirma Jung. Podemos simplesmente constatar o que acreditamos que elas sejam e descrever da melhor maneira possível como funcionam".(1:27) Os enigmas da psique são infinitos, a começar pelo seguinte sonho que me foi relatado por uma pessoa cujo nome prefere manter em sigilo: ela caminhava nua na praia, seguia para uma caverna e, em seguida, ouviu o nome lemanjá. Interpretou que a nudez seria necessidade de proteção e atenção com o corpo, com a saúde, por isso era preciso observar mais as ameaças à integridade física. $O$ sonho seria um aviso para usar preservativo sexual. Vivia essa tensão nesse momento. $O$ mar, na tradição religiosa brasileira, é a personificação da deusa lemanjá, responsável pelo enunciado de carinho, cuidado e manutenção da vida, buscando equilíbrio e bem-estar diante das dificuldades existenciais nas quais todos estamos imersos.

"Há mais mistérios entre o céu e a terra do que supõe nossa vã filosofia" - dizia Shakespeare ${ }^{(1)}$ no século XVI. Ainda na peça dramática, Hamlet, o espírito do rei falecido vem avisar a seu filho "enlouquecido" e sucessor que tomasse cuidado com seus algozes, e lhe diz quais procedimentos adotar dali em diante. A literatura, o cinema, as novelas, as artes plásticas se responsabilizam mais que a ciência pelo tema sonhos-mente, destacando muitas vezes seu papel de guardião, conselheiro, "ancestral milenar".

Existe uma lista infindável de filmes sobre o assunto, tanto nos Estados Unidos e Europa quanto no Japão. O mundo desenvolvido já descobriu que o corpo é capaz de proezas, basta conhecê-lo, ouvir, planejar. No quesito planejamento, os referidos países têm sido bem sucedidos. Descobriram que as complexidades desconhecidas do corpo produzem lucro, cultura, arte e fórmulas científicas. Da linha suspense dos filmes norte-americanos, nascem os dividendos com a produção da indústria cinematográfica norte-americana, tornando-a mais opulenta, lucrativa e hegemônica em função das pesquisas e experiências sobre sonhos. A telessérie Medium, exportada para o mundo, é um exemplo de tamanha fartura dos Estados Unidos. A atriz Patrícia Arquette interpreta uma investigadora policial que, ao dormir, visualizava todas as cenas de crimes cometidos: assaltos, assassinatos, infidelidades conjugais, sequestros, tramas sórdidas. Com explosão de sucesso, a série foi exibida de 2005 a 2011 pelas companhias NBC, CBS, Universal Chanel e outras empresas midiáticas. Esse boom empresarial demonstra o quanto o tema sonhos é vigente, pragmático, já não cabem falácias de ser assunto de supersticiosos e povos atrasados. Ao contrário, é objeto científico, embora no Brasil haja pouca atenção e produções acadêmicas deste campo do conhecimento. Então, é preciso estudar as manifestações oníricas, haja vista que, segundo Segundo Milhorim et al $\left.\right|^{(12: 2)}$ - "por meio de uma seleção sistemática nas bases Lilacs, SciELO e PePSIC, entre 2001 e 2011 - foram recuperados oito artigos. Constata-se, de forma geral, a pequena quantidade de estudos destinados especificamente ao tema". Enfim, devemos método de apreensão em pesquisa ao tema sonhos, para meIhor abordá-lo, para gerar know how e renda. No exterior, inúmeros são os artigos, livros, filmes, publicados acerca desse objeto para o conhecimento.

Os sonhos podem ser chamados de religiosos, mas fundamentalmente são terapêuticos, harmonizadores, éticos, morais. Longe de ser uma moral essencial, castradora, eterna, mas uma moral mutável que se faz e refaz conforme as circunstâncias e desafios - uma moral telúrica, pragmática. $\mathrm{O}$ objetivo é a adaptação, fortalecimento e mudança do corpo para o enfrentamento cotidiano. Abstinência momentânea de sexo e drogas, por exemplo, tem mais caráter de manutenção da saúde integral e menos de aspecto religioso. As respostas estão dentro dos seres humanos de qualquer lugar, estão na subjetividade silenciosa e meditativa - como anticorpos e células que se renovam para se defenderem de agressões ao organismo e à coletividade. Quem sonha reside em uma cidade, um território político e econômico, tem um corpo físico e psíquico para administrar. E, sem dúvida, o grande suporte filosófico, existencial e orgânico reside 
nas expressões oníricas. Portanto, é preciso bem administrá-las.

\section{A LINGUAGEM PLURISSIGNIFICATIVA DOS SONHOS}

"Os símbolos, segundo Novaes e Rudge, são significantes de um pacto que constitui significados, ou seja, eles demarcam o conjunto das significações atribuídas pela cultura na qual o homem irá inserir-se". ${ }^{13: 5)}$ Cada cultura tem uma chave para abri-los. Há muitas culturas e povos diferenciados na Europa, no Brasil, nos Estados Unidos, África e Ásia. Cada povo, cada corpo físico produz enunciados conforme seu entendimento e interpretação da vida. Portanto, não basta universalizar "cientificamente" a partir da experiência de Viena e Estados Unidos. Em cada país existem vozes identitárias diferenciadas, com métodos e chaves interpretativas próprios. Enfim, existem símbolos e sinais que só podem ser compreendidos dentro de contextos culturais, de grupos religiosos, por exemplo, que os consideram sinalizadores e tradutores de suas experiências.

O exercício onírico funda-se em linguagem desviante, criativa, meditativa - cria um novo pensar que transcende as ideologias do estado de vigília e o aprisionamento da língua. Ferdinand de Saussure, ${ }^{14}$ no Curso de Linguística Geral, advertia-nos sobre a incompatibilidade ou arbitrariedade entre signo linguístico e sentido (conteúdo). Essa é uma discussão antiga. Em narrativas de sono, a palavra ou significante se transmuta, movimenta-se, porque inúmeras palavras na vigília têm uma direção sinuosa, incompleta. Nelson Rodrigues ${ }^{(15: 13)}$ no conto "O pediatra" mostra como o termo "miserável" é sinônimo de "excelente". A metáfora transcreve a realidade não percebida pela tradição do pensar. Instaura nova interpretação paralela à mudança imediata que ocorre, reescrevendo, desorganizando o pensar tradicional. Enfim, a própria língua produzida pelo estado de vigília, pelo falar comum produz uma referência paradoxal, incerta, dada a redoma do pensar e, consequentemente, das palavras em relação ao objeto que indicam. Imaginem a distância que existe entre metáforas dos sonhos e interpretação racional, consciente. Há grande abismo e por isso incapacidade de interpretarmos os sonhos com nossos instrumentos na vigília. Segundo Nietzsche, "a língua está construída sobre os mais ingênuos preconceitos [...] e que o pensamento racional é um interpretar segundo um esquema". ${ }^{16: 228-229)}$ Então há muito esforço a ser feito, desafios, pesquisas inclusive sobre linguagem onírica. A realidade é extensa, densa demais para caber no corpo, na história, na ciência moderna.

A linguagem onírica dribla e contorna o estado de vigília ou consciência, para instaurar o novo real anunciado pelo enunciado. A frase de efeito surge em meias palavras, incompletas (metonímicas), inversas, com a fórmula necessária para a resolução da equação, do conflito. O falar dos sonhos, além de antitético, extrapola o cotidiano e o significante, pois é emendada e figurativa, de modo que o nexo da vigília, da consciência é insuficiente para explicar o sentido da linguagem onírica. A complexidade revela uma distância entre a consciência que é nova e os sonhos, que são antigos (instintivos). Os sonhos revelam muitos sujeitos falantes. O Novo consciente entende mal o Velho onírico que tropeça na estrutura mental ideológica e conservadora do Novo "racional". Há algo milenar que fala dentro de um corpo novo, sujeito recente. Aí ocorre a confusão, a distância espaço-temporal, aquilo que denominamos metáfora, abstração, códigos da linguagem, imprecisão. Como foi discutido anteriormente, nem toda linguagem onírica é simbólica ou arquetípica. Por vezes trata diretamente dos conteúdos do estado de vigília, apresentando-lhe soluções e terapias diversas.

Não temos tido êxito em vencer as barreiras da língua, mas isso não significa que o objeto inexista. Nem sempre é possível denominá-lo precisamente, mediante eficiente método de apreensão. 


\section{CONSIDERAÇÕES FINAIS}

Sonhar é uma experiência humana universal. Os sonhos dão estabilidade psíquica e organizam a vida social dos indivíduos que compreendem seus códigos. Embora seja um fenômeno planetário, cada comunidade tem know how e métodos próprios para ler e decodificar os labirintos da linguagem onírica de seus pares identitários. Portanto, universalizar a problemática e soluções em torno dos sonhos, a partir de experiências locais de consultórios não é modo adequado de cientifizar uma pesquisa. Alteridade deveria ser componente científico. O Outro existe, mesmo que não o conheçamos ou discordemos do modo como vive.

A ciência deve responder por que um corpo de sangue, secreções e sonhos é capaz de sintetizar o passado, presente e falar do futuro. $O$ corpo precisa continuar sendo pesquisado, pois a mente possui uma vasta realidade para ser melhor conhecida sem ser tachada de metafísica quando suas expressões forem desconhecidas. Chamemos de realidade-físico-química, oculta, silenciosa. Analisar a linguagem onírica não deve ser apenas atribuição das umbandas, maçonarias e templos místicos. As imagens mentais desenvolvidas pela mente nos mais diversos estados produzem soluções, curas, respostas para problemas individuais e coletivos de uma comunidade. São por isso respostas ao presente e ao futuro; anunciam uma nova existência.

Disciplinas acadêmicas como História dos Sonhos ou Fenomenologia dos Sonhos, Literatura dos Sonhos, Ciência dos Sonhos e afins seriam úteis para elucidação de muitas questões e incógnitas.

Paralela à nossa civilização informatizada e química existe outra "ciência": a do transe, a dos sonhos, da Jurema - meditativa e silenciosa - mas aberta, livre para ser investigada. Tudo produzido pelos poderes inerentes ao corpo humano. Então é importante que as psicologias utilizem olhar antropológico para melhor entender as propriedades das limitações psíquicas de um povo, de um indi- víduo, sem recusa por conhecer as potencialidades do organismo humano infinito.

\section{REFERÊNCIAS}

1. Jung CG. O homem e seus símbolos. $5^{\mathrm{a}}$ ed. Tradução Maria Lúcia Pinho. Rio de Janeiro: Nova Fronteira; 1964.

2. Bacon F. Novum Organum (XLI). São Paulo: Abril Nova Cultural; 2000. (Os pensadores)

3. Bulkeley K. Sacred Sleep: Scientific Contributions to the Study of Religiously Significant Dreaming. In: Barret D, Mcnamara $P$, editors. The New Science of the Dreaming. Chap 3. P 3-71. Westport, Conn: Praeger Publishers; 2007. [Cited 2016, Feb 12]. Available from: http://www.kellybulkeley.com/pdfs/ sacredsleep.pdf

4. Jung CG. Os arquétipos e o inconsciente coletivo. [Trad. Maria Luíza Appy, Dora mariana R. Ferreira da Silva]. $2^{\mathrm{a}}$ ed. Petrópolis, RJ: Vozes; 2000. (Obras Completas de C. G. Jung, v. 9/1).

5. Jung CG. Símbolos da transformação. Trad. Eva Stern. Petrópolis, RJ: Vozes; 1986. (Obras Completas de C. G. Jung, v. 5).

6. The Diamond Jubilee Thames Pegeant. 2016. Disponível em https://www.youtube.com/ watch?v=bmGqWdYEw_w

7. Hartmann E. The Nature and Functions of Dreaming. New York: Oxford Universal Press; 2011.

8. Festa da Mestra Ritinha da Rua da Guia. 2016. Disponível em https://www.youtube.com/ watch?v=rvDIXV5DS44

9. Good News Bible: The Bible in Today's English Version. New York: American Bible Society; 1976.

10. Jung C G. Psicologia e alquimia. Petrópolis, RJ: Vozes: ????. (Obras Completas de C. G. Jung, v. 12). Originalmente publicado em alemão em 1944/1994.

11. Shakespeare W. Romeu e Julieta; Macbeth, príncipe da Dinamarca; Otelo, o Mouro de Veneza; Traduções de Cunha FCA, Mendes O. São Paulo: Abril Cultural; 1981. 
12. Milhorin TK, Karin A, Casarini KA. Os sonhos nas diferentes abordagens psicológicas: apontamentos para a prática psicoterápica. Rev. SPAGESP. 2013[acesso em $14 \mathrm{fev}$. 2016];14(1):79-95. Disponível em: http:// pepsic.bvsalud.org/scielo.php?script=sci_ arttext\&pid=S1677- 9702013000100009.

13. Novaes $B$, Rudge AM. A função da linguagem em Bakhtin e Lacan. Tempo psicanál. 2007 [acesso em 16 fev. 2016];39:157-178. Disponível em: http://www.cefetsp.br/edu/sertaozinho/ revista/volumes_anteriores/volumelnumero2/ ARTIGOS/volumel, número2, artigol.pdf
14. Saussure F. Curso de linguística geral. Tradução de Antônio Chelini, José Paulo Paes, Izidoro Blikstein. São Paulo: Cultrix; 2006.

15. Rodrigues N. A vida como ela é... O homem fiel e outros contos. São Paulo: Companhia das Letras; 1992.

16. Nietzsche F. Sabedoria para depois de amanhã. São Paulo: Martins Fontes; 2005. 